Kuramsal Derleme

\title{
Projektif Yöntem Olarak Rorschach Testi ile Psikozun Íncelenmesi
}

Kübra Göçer ${ }^{1 *}$, İ́stanbul Üniversitesi, Edebiyat Fakültesi, Psikoloji Bölümü, İstanbul, Türkiye

\begin{tabular}{|c|c|}
\hline Makale Bilgisi & Öz \\
\hline $\begin{array}{l}\text { Anahtar } \\
\text { kelimeler: }\end{array}$ & $\begin{array}{l}\text { Klinik psikoloji uygulamalarında psikopatolojileri tespit etmek amaçlı çeşitli } \\
\text { metodlar kullanılmaktadır. Rorschach Testi, niteliksel veriler sunan ve bir projektif } \\
\text { test olarak bilinen, bu metodlardan bir tanesidir. Öncelikle projektif testlerle beraber }\end{array}$ \\
\hline $\begin{array}{l}\text { Rorschach Testi, } \\
\text { psikoz, paranoid } \\
\text { şizofreni }\end{array}$ & $\begin{array}{l}\text { Rorschach Testi'nin tarihçesi, uygulanışı ve yorumlanması tanıtıldıktan sonra, } \\
\text { psikozun bu testin protokollerine nasıl yansıdığı ele alınacaktır. Psikotik } \\
\text { yapılanmaların ortak özellikleriyle beraber psikotik endişe incelenecektir. Bu ortak } \\
\text { özelliklerin incelenmesinin merkezinde, Chabert tarafından } 5 \text { ana özellik olarak } \\
\text { birleştirilen ve Palem'in şizofreniyle çalışmalarına dayanan kategoriler yer } \\
\text { almaktadır. Gerçeklik algısı, zihinsel süreçler, kimlik ve beden imgesi, koruma } \\
\text { kalkanları ve pregenital ilişkileri alanlarında psikotik bireylerin ortak deneyimleri } \\
\text { bulunmaktadır ve bunlar Rorschach Testi’ne yansımaktadırlar. Yanı sıra, test } \\
\text { protokollerinin iki çeşit olarak ayrıştırılabildiği bilinmektedir. Şizofreni protokolleri } \\
\text { ruhsal çölleşmeyi barındırmaktadır. Paranoid şizofreni protokolleri ise zengin bir } \\
\text { içsel dünyayı sunmalarına rağmen, altta yatan kırılgan psikotik yapı belirgindir. Bu } \\
\text { iki test protokol ceşidi son olarak ele alınmaktadır. }\end{array}$ \\
\hline
\end{tabular}

Abstract

In clinical psychology practices, various methods are used in order to detect psychopathologies. The Rorschach Test, which offers qualitative data and is known as a projective test, is one of these methods. First of all, after introducing the history, application and interpretation of the Rorschach Test together with projective tests, , how psychosis is reflected upon the protocols of this test will be addressed. Common features of psychotic structures as well as psychotic anxiety will be investigated. At the centre of these common features, the 5 main categories integrated by Chabert and based on Palem's publications with schizophrenia are located. Schizophrenic individuals have common experiences in the areas of reality perception, cognitive processes, identity and body image, protection shield and pregenital relations. Besides, it is known that test protocols can be divided into two types. Schizophrenia protocols embody psychic drought. On the other hand, although paranoid schizophrenia protocols present a rich innerlife, the underlying fragile psychotic organization is apparent. These two protocol types will be eventually discussed.

\footnotetext{
*Sorumlu Yazar, İstanbul Üniversitesi, Psikoloji Bölümü. Balabanağa Mah. Ordu Cad. No:6 Laleli Fatih / İSTANBUL e-posta: kgoecer@gmail.com

DOI: $10.31682 /$ ayna.422666

Gönderim Tarihi (Received): 10.05.2018; Kabul Tarihi (Accepted): 01.09.2018

2148-4376/ All rights reserved.
} 


\section{Giriş}

Ülke ve dünya genelinde psikolojide bireylerin kişiliğine dair bilgi edinmek amaçlı araştırmalarda çoğunlukla ya objektif ya da projektif testler kullanılmaktadır (Pomerantz, 2013). Objektif testler niceliksel araştırmaların hizmetindeyken, projektif testlerle bireyi ve onun ruhsal dinamiklerini olabildiğince keşfetmeye çalışırız (Morris \& Maisto, 2007). Böylelikle, bir projektif test içsel çatışmaların getirdiği düşünce ve duygulanım hareketlerini kapsamayı hedeflemektedir. Objektif testlerde belli bir sorunun cevabına ya da özgül bir bilgiye ulaşılmak istenilirken, projektif testlerde ise gelen zengin malzeme değerlendirilir ve bilinçdışının derinliklerine ulaşılmaya çalışılır (Morris \& Maisto, 2007). Bu testlerde, objektif olanlarla kıyaslandığında, yönlendirme kısıtlı düzeydedir (Anzieu \& Chabert, 2011). Aynı zamanda ucu kapalı sorulara değil, ucu açık sorulara cevap verilmektedir. Rorschach Testi’nde 'Bu kartlar size neler hayal ettirdi' sorusundan anket sorusuna kadarki alan düşlem ve sembolizasyon kapasitesiyle doldurulmaktadır. Anzieu ve Chabert (2011) projektif testlerde yönergenin belirsizliğinden ve çağrışımsal/ zamansal kısıtlamanın bulunmamasından dolayı oluşan boşluğun kişisel yetenek ve derin kaynaklar kullanılarak doldurulması beklendiğini dile getirmektedirler.

Tuber (2012) çalışmalarında bazı araştırmacıların projektif testlerin psikometrik özelliklerini eleştirdiklerine değinmektedir. Kendisi de bu testlerin geçerliliğinin bir araştırmacının beklentilerini karşılamadığını kabul etmektedir. Diğer testlerle karşılaştırıldığında, Rorschach veya TAT’nin testten ziyade, bir insanın deneyimlerini anlamak amaçlı geliştirilmiş yöntemler olduğunu savunmaktadır. Yazara göre, projektif yöntemler bizim daha iyi bir fenomenolog olmamıza, hastanın deneyimleri ve semptomları arasında bağlantı kurmamıza yardımcı olacak araçlardır.

\section{Tarihçe}

Anzieu ve Chabert (2011) mürekkep lekelerinden test oluşturma fikrinin Leonardo da Vinci’ye dayandığını dile getirmektedirler. 1895 yılında Binet ve Henri, Da Vinci’den esinlenerek, bu tarz bir test yayımlarlar. Sonradan birçok mürekkep lekesinden oluşan testin geliştirilmesine rağmen, İsviçreli Hermann Rorschach'nın sanatsal yeteneklerini ve tıp alanındaki deneyimlerini bütünleştirerek 1918 yılında oluşturduğu Rorschach kartları zamanla başarıya ulaşıp kabul görür (Anzieu \& Chabert, 2011). H. Rorschach 288 hastayla beraber 117 normal kişiye bu testi uygular ve araştırmalarını 1921 yllında Psikodiagnostik kitabında yayımlar. Bu süreçte yayıncı bulmakta zorluk çeker. Bir yıl sonra mide iltihabından dolayı hayatını kaybeder ve ölümünden sonra bu test İsviçre'de beklediği başarıyı elde edemez (Anzieu \& Chabert, 2011). 
Rorschach kartları geliştirildikten sonra, iki ülkede farklı çalışmaların yürütülmesi Rorschach Testi için iki ana yorumla/ puanlama sisteminin yaygınlaşmasına neden olur. Günümüzde, Birleşik Devletler'de ağırlıklı olarak psikometrik bir puanlama sistemiyle çalışlırken, Fransa'da psikanalitik teoriyle bütünleştirilmiş bir puanlama ve yorumlama sistemine ağırlık verilmiştir (İkiz, 2017). 1936 yllında Birleşik Devletler'e Rorschach Testi’ni tanıtan Beck olmuştur (Emmanuelli ve De Tychey, 2017). Klopfer 1939 yllında New-York'ta Rorschach Enstitüsü (Rorschach Institute) adı altında araştırma merkezini kurar. Birleşik Devletlerde Rapaport, Klopfer, Piotrowski, Beck ve Schafer’in araştırmalarının önemini vurgulamak gerekmektedir (Emmanuelli ve De Tychey, 2017). 1974 yllından sonra John Exner'in geliştirdiği Genel Rorschach Puanlama Sistemi (Rorschach Comprehensive Scoring System), istatistiksel verilere ve davranışsal etkenlere dayanarak geliştirilen ampirik bir Rorschach değerlendirme sistemi kullanılmaya başlandı (Emmanuelli ve De Tychey, 2017). Exner'in ölümünden sonra Birleşik Devletler'de psikometrik özelliklerin odak noktası olduğu Rorschach Performans Değerlendirme Sistemine (Rorschach Performance Assessment System) geçildi (İkiz, 2017). Fransa'da Rorschach Testi ile ilgili çalışmalar 1950 yılında Société du Rorschach et des Méthodes Projectives de Langue Française ile başlar. Testin Fransızca konuşulan ülkelerde yaygınlaşması, Loosli-Usteri ve araştırmacaların Fransızca bir terminoloji oluşturmalarıyla 1965 yllında gerçekleşir (Emmanuelli ve De Tychey, 2017). 1950’lerde, Lagache ve Minkowska tarafından çalışmalar yürütülür. 1960 yılından sonra Didier Anzieu, Nina Rausch de Traubenberg, Vica Shentoub, Rosine Debray ve Catherine Chabert gibi araştırmacıların yardımlarıyla Rapaport'un attı̆̆ı temellerle Paris Okulu'nun psikanalitik kurama dayalı Rorschach ve TAT çalışmaları yürütülür ve geliştirilir (Société du Rorschach et des Méthodes Projectives de Langue Française, t.y.).

\section{Psikanalitik Kuram ve Rorschach Testi}

İkinci Dünya Savaşına kadar Rorschach Testi ateorik yaklaşımlarla değerlendirilmekteydi (Sugarman \& Kanner, 2000). Rapaport, Gill ve Schafer çalışmalarıyla Rorschach Testi'ni psikanalitik kurama entegre ettiler (Sugarman \& Kanner, 2000). Lerner (2007), Rapaport'un Rorschach ve Tematik Algı Testi’nin psikometrik değerlendirmenin, psikanalitik içerik analiziyle bütünleştirmesindeki çalışmalarını vurgulamaktadır. Rapaport'un öğrencisi Schafer, Freud'un oral, anal ve fallik psikoseksuel gelişim evrelerine odaklanıp, bu evrelere göre yanıtların nasıl yorumlanabileceğine dair çalışmalar yürütmüştür (Sugarman \& Kanner, 2000). Freud (1901/ 1976) Düş Üzerine adlı yazısında rüyaların görünür ve gizil içeriklerini incelemiştir. Minkowska, Monod, Mac Cully, Anzieu ve Rausch de Traubenberg rüyaların sembolik içeriklerini, Rorschach kartlarına aktarıp, her kartın görünür ve gizil içeriklerini geliştirdiler (Anzieu \& Chabert, 2011). Güncel Rorschach Test’iyle 
yürütülen çalışmalar, bu araştırmacıların katkıda bulunduğu kuramsal bütünleştirmelere dayanmaktadır.

Rorschach Testi'nin uygulanış biçimine dair temeller Rapaport tarafından geliştirilmiştir (Lerner, 2007). Tüm psikolojik testler için geçerli olan ışık ve ses gibi ortamının gereklilikleri sağlandıktan sonra, Fransız Okulu'nun yönergesine dayalı olarak kişiye şu sözler yöneltilmektedir: 'Şimdi size bir dizi kart göstereceğim. Bu kartların size neler düşündürttüğünü, neleri hayal ettirdiğini söyleyiniz' (İkiz, 2017, s.61). Her karttan sonra, yanıtları lokalize edebilmek ve bireyin çağrışımlarının eklemlenmesine yardımcı olmak için, anket yapılmaktadır (İkiz, 2017). Rorschach Testi toplam 10 adet mürekkep lekesi gibi gözüken karttan oluşmaktadır (İkiz, 2017). Anzieu ve Chabert (2011) kartlarda hem somut ve net şekiller bulunduğunu, hem de yorumlama ve hayal gücünü tetikleyecek belirsizliği içerdiğini dile getirirler. Böylece, kartlara verilen yanıtlar kişinin algısal ve projektif faaliyetlerini aktarmaktadırlar. I, IV, V, VI ve VII numaralı kartlar siyah beyazdır (İkiz, 2017). II ve III numaralı kartlar siyah ve kırmızıdır. Son kartlar ise VIII, IX ve X pastel renklerdedir. Her kart simetri içermektedir, bazı kartlarda bu simetri daha belirgindir bazılarında ise ayna veya tekrar gibi gözükmektedir. Baskın renklerin olduğu kartlarda, II ve III numaralı kartlarda, kırmızı rengin etkisiyle, şiddet ve cinsel içerikli yanıtların verilmesi kolaylaşmaktadır (İkiz, 2017). Pastel renkli kartlar ise regresyona izin vermektedirler. Test uygulandıktan sonra, kişinin verdiği her yanıt kodlanmaktadır. Yanıtların analizi, hem bu istatistiksel verilere dayanan kodlamaya hem de çeşitli kuramcılar tarafından geliştirilen içerik analizine dayanmaktadır (Sugarman \& Kanner, 2000). Belirli ruhsal yapılanmaların tespiti birbirini tamamlayan bu iki analize dayanmaktadır.

Psikanalitik kuramla birlikte Rorschach Testi’ndeki tanı kriterleri DSM-V kriterleriyle birebir uyuşmamaktadır (İkiz, 2017). Nevrotik, sınır ve psikotik yapıların altında obsesif, histerik, fobik, borderline, narsisistik, psikosomatik, şizofrenik veya paranoid şizofrenik tanılar bulunmaktadır (İkiz, 2017). Bu testlerin uygulanmasının ve yorumlanmasının amacının teşhisten ziyade, kişiyi belli semptomlara sürükleyen nedenleri açılağa kavuşturmak olduğunu unutmamak gerekir (Tuber, 2012).

Patolojik ruhsal süreçlerin yanı sıra, Rorschach Testi çatışma ve endişe türü, anne ve baba imagoları, beden imgesi, kimlik, bilhassa cinsel kimlik, düşünce süreçleri, dürtüler, duygulanım, nesne ilişkileri ve savunma düzenekleri hakkında bilgi vermektedir (İkiz, 2017). Uygulamada Rorschach Testi'nin Tematik Algı Testi (TAT) ile birlikte ele alınması önerilmektedir (Société du Rorschach et des Méthodes Projectives de Langue Française, t.y.). 


\section{Psikoza İlişkin Rorschach Test Bulguları}

Uluslararası Psikanaliz Sözlüğüne (International Dictionary of Psychoanalysis) bakıldığında, psikozu belirleyen ana unsurlardan bir tanesi 'yok olma endişesidir' (annihilation anxiety) olarak nitelendirilmektedir (Mijolla, 2005). 'Yok olma endişesi' dağılma, parçalanma, çürüme ve ruhsal kontrolü kaybetme korkusunu açıklamaktadır (Mijolla, 2005). Klein'ın psikotik endişe olarak adlandırdığı bu durum, nevrotiklerin kastrasyon endişesinden ve sınır yapıların nesne kaybı endişesinden farklıdır (Mijolla, 2005; İkiz, 2017). Rorschach Testi'nin protokollerinde yaygın bir biçimde bu endişenin varlığı, psikoza işaret etmektedir. İkiz (2017) 'yok olma endişesini' yaşayan bireyin, ruhsal dünyasının çökmesinden korktuğunu ve hastada yeterli uyarı kalkanı bulunmadığından, içten ve dıştan gelen uyaranlara karşı yetersizlik ortaya çıktığını dile getirir.

Freud (1916/ 1963) şizofrenide bilinçdışının, nevrotiklerle kıyaslandığında, daha belirgin bir şekilde ifade edildiğine değinir. Ego'nun hakimiyetinden ziyade, bilinçdışı malzemenin ve birincil süreçlerin kişiyi yönlendirmesi söz konusudur (Freud, 1916/ 1963).

Catherine Azoulay (2008) Palem’in şizofrenlerle yaptığı araştırmalar sonucunda bu tarz protokollerin 13 ortak özelliğinin bulunduğuna değinir. C. Chabert 13 maddeyi 5 sınıf altında birleştirir (akt., Azoulay, 2008). Bahsi geçen sinıflar takriben tüm şizofreni protokollerinde, bulunur ve şizofreninin genel kuramsal özelliklerini de içerir.

İlk olarak, Chabert şizofrenide gerçeklik algısının bozulmuş olmasından bahseder (akt., Azoulay, 2008). Rorschach Testi'nde doğru biçim yanıtlarının oranın (F+\%) düşük olması ve V. Kartın (gerçeklik ve kimlik kartı) reddedilmesi gerçeklikle bağın kopmuş olduğuyla veya kopmaya başladığıyla ilişkilendirilir (Azoulay, 2008). Bununla birlikte, perseverasyonlar (tekrarlamalar) bozulmalara işaret eder (Azoulay, 2008). Bunlar, bir önceki kartın tepkisinin devamı niteliğinde alan tepkilerdir (İkiz, 2016). Gerçeklik farklı uyaranlardan oluşmaktadır. Farklı uyaranlara farklı tepkiler vermekteyiz. Bu test de kişiye her kartla yeni uyaranlar sunmaktadır. Ancak psikotikler her kartı aynıymış gibi algılarlar ve aynı konu üzerinde durup tekrarlamalarda bulunurlar (İkiz, 2016). Perseverasyonlar gibi, kontaminasyon (Fransizca contaminé: bulaşmış, bozulmuş) yanıtları da dış dünyayı kavramakta zorlukların yaşandığını gösterirler (İkiz, 2016). Bu tarz yanıtlar iç içe geçmiş, fakat normalde birbirinden bağımsız olan, tasarımları içermektedirler (İkiz, 2016). Örneğin, "kelebeğin karnında bir zürafa yavrusu var" ya da "Timsah bedeninde insan kolu var" kontamine cevaplardır. Bu tip kontaminasyon içeren cevaplar, gerçekliği uygun bir şekilde algılamada önemli olan iç ve dış sınırların kaybolduğuna işaret eder.

İkinci olarak, Chabert şizofrenide bilişsel ve düşünce süreçlerinde eksikliklerden bahseder ve bu düşünceler arasında kopuk bağların olduğunu vurgular (akt., Azoulay, 2008). Bilişsel kapasitenin yetersizliği ve düşüncelerin uygunsuz birleştirildiğini konfabülasyonlarda 
(masallamalar) görmekteyiz (Azoulay, 2008). Kişi, doğru bir biçimden yola çlkarak keyfi genellemelerde bulunur. Örneğin, "Bu bir köpek çünkü bacakları var”. Biçimi doğru bir şekilde algılar ve köpek genellemesinde bulunur. Oysa ki, köpeği diğer hayvanlardan ayırt eden özellik bacak değildir. Soyutlamalar da bu protokollerde eksikliklerin göstergesidirler (Azoulay, 2008). "Burada bir şeylerin bozulduğunu görüyorum” ya da "Güçsüzlük var bu kartta" gibi soyut yanıtların kodlaması mümkün değildir ve bu tarz cevaplar psikozda testin yarattığı endişeye karşı bir savunma olarak değerlendirilmektedir (İkiz, 2017). Malzeme tehdit edici olmaya başladığında, bilişsel işlevlerin yetersizliğinden dolayı, kişi uyaranın içeriği ile mesafe koyarak kendini korumaya almaktadır. Verilen tepkideki kopukluklar ve düşünceler arasında bağlantısızlık, protokollerde K (hareket) cevaplarının olmamasıyla desteklenir (Azoulay, 2008). Hareketin olmaması durağanlıkla beraber düşünceler arasında bağ kurulamadığını gösterir. Düşünce bağlarını kurabilmek için hareket gereklidir.

Yukarıda ele alınan sınıftan ayrı olarak, şizofrenide kimlik, beden imgesi ve özdeşimle ilgili sorunları, Chabert üçüncü bir sınıf altında birleştirir (akt., Azoulay, 2008). Özdeşim kurulması ve kendilik tasarımının oluşması için, bir diğerinin olması gerekir. K cevaplarının olmaması, ötekinin varlığını reddetmek anlamını taşır. Çünkü hareket için genellikle başka bir özne gerekir (İkiz, 2017, s. 187). Şizofrenide kimlik ve beden imgesi sorunları protokollerde sıklıkla anatomi cevaplarının verilmesiyle desteklenmektedir (Azoulay, 2008). Anatomi cevapları beden içine dair cevaplardır ve psikotik bireyler bu cevapları ölüm ve hastalık temalarıyla birleştirerek psikotik endişeyi yansıtmaktadırlar (İkiz, 2017). Örnek olarak "Dışarıya çıkmış parçalanmış bağırsaklar” veya "kanayan akciğerler” gibi cevaplar verilebilir. V. Kartın reddi sadece gerçeklik algısının bozulduğunu değil, aynı zamanda kimlikle ilgili problemleri de göstermektedir (Azoulay, 2008). Bu kart hem gerçeklik hem de kendilik kartıdır. Sağlıklı kişilerin kolaylıkla bu karta cevaplar verebilmelerine karşın, bu kart psikotikleri çok zorlamaktadır.

Chabert, dördüncü sınıf olarak şizofrenide uyarı kalkanlarında ve kapsayıcılıkta yetersizlikle beraber duygulanımın ayrışmamasından bahseder (akt., Azoulay, 2008). Lerner ve Lerner (1982) şizofrenide inkâr, yansıtma, yansıtmalı özdeşim ve yarılma gibi ilkel savunma düzenekleri kullanımına dair çalışmalar yürütmüşlerdir. Bu düzenekler, uyarı kalkanlarındaki yetersizliği beraberinde getirir. C yanıtları renklere karşı hassasiyetle birlikte duygulanımın yansımasıdırlar ve sıklıkla biçim yanıtlarıyla birleştirilirler (İkiz, 2017). Böylece duygulanım tasarıma bağlanmış olur. Şizofreni protokollerinde ise, saf C yanıtları yoğun duygulanımın taşkınlığını ve onların kontrol edilemediğini gösterir (Azoulay, 2008). II ve III numaraları kartlarda cinsel ve şiddet içerikli cevaplar verilmektedir, fakat şizofreni protokollerinde sembolizasyondan uzak saldırganca cevaplar verilir. "Her yere kan sıçramış" gibi cevaplar saf C olarak kodlanır ve duygulanımın bağlanamadığını gösterirler. Bununla 
beraber, Rorschach Testi'nde psikotiklerin renkleri isimlendirmeleri, canlı içeriklerle dolu bir duygusal dünyadan uzak, kopuk ve yoğun duygulanımı göstermektedir (Azoulay, 2008). K (hareket) cevaplarının oranın C (renk) cevaplarının oranıyla karşılaştırıldı̆̆ TRI (Type de Résonance Intime) formülünde de, şizofreni protokollerinde C’lerin oranı çoğunlukla daha yüksektir (Azoulay, 2008).

Son nokta olarak, Chabert psikozun erken dönem problematiğine değinmektedir (akt., Azoulay, 2008). Bu dönemdeki anneyle olan ilişkinin travmatik etkisi, VII ve IX numaralı kartlara sıklıkla verilen şok tepkisiyle teste yansıtılır (Azoulay, 2008). Genellikle, VII. Kart annesel tasarımları harekete geçirir, IX. Kart ise arkaik anneyle olan ilişkiyi bize gösterir (İkiz, 2017). Psikozda bu kartların şokla karşılanması, anneyle ilişkinin sorunlu olduğunu vurgular. IX. Kartta aynı zamanda sıklıkla kişisel referansların verilmesi, "Bu kartı hiç beğenmedim” gibi, kişinin malzemeyle yüzeysel ilgilenmek istediğini ve ilkel döneme dayalı yoğun duygulanımla yüzleşmek istemediğini gösterir (Azoulay, 2008).

Chabert'in ayrıştırdığı beş sınıf takriben tüm şizofreni protokollerinde bulunmaktadır. $\mathrm{Bu}$ genel özelliklerin dışında şizofreni protokollerini, ketlenmiş protokoller ve zengin protokoller olarak, ikiye ayırabiliriz.

\section{Ketlenmiş ve Zengin Şizofreni Protokolleri}

Aynı makalede, Azoulay (2008) iki çeşit protokolün farklılıklarını inceler. Ketlenmiş protokollerle başlayarak, bu bireylerin üretimle birlikte sözelleştirme kapasitelerinin zaylf olduğunu söyler. Yanıt sayısının az olmasının yanı sıra, perseverasyonlar diğer protokollere göre daha sık görülmektedirler (Azoulay, 2008). Öyle ki, bunlar yaratıcılığın da azaldığını işaret ederler. Biçimsel yanıtlara verilen önem, ketlenmiş şizofreni protokollerinde merkezi bir role sahiptir (Azoulay, 2008). Determinantlar arasında, ya biçim ya da hareket cevabı verilebilir. Hareket cevaplarının az verildiği bilgisine yukarıda değinildi. Psikotikler diğer seçenek olarak, biçim yanıtlarına ağırlık vermektedirler. Özellikle stereotipik, yaratıcılıktan ve öznellikten uzak biçim yanıtları sunulmaktadır (Azoulay, 2008). Bazen de, depresif ve içeriksiz biçimler verilmektedir. Bu biçim yanıtlarıyla, Azoulay (2008)'ın sözleriyle "kapsayanı olmayan kapsananlar” gibi, psikotik birey anlamsız olan dış dünyaya tutunmaya çalışmaktadır. Hareket cevaplarının kısıtlı oranda bulunması, sadece bir ötekinin inkârı anlamına gelmez. Aynı zamanda ruhsal dünyanın donukluğunun yansımasıdır. Dürtünün durmasıyla, psikotik bir çölleşmenin gerçekleşme riskini taşımaktadır. Azoulay (2007) ruhsal çölleşmeyi zamansallık çerçevesinden incelemektedir. Doğal gelişimde, ergenin zamansallı̆̆a yerleşmesi sonucunda içsel süreçler harekete geçer (Azoulay, 2007). Kişi zamanın akışının farkına varır ve kendini bu akışın içerisinde konumlandırmaya başlar (Azoulay, 2007). Geçmiş, şimdi ve gelecek arasında bağlantılar kurmaya başlar. Şizofrenin başlangıç sürecini 
deneyimlemiş olan ergenlerde, depresif duyguların dinamik içsel dünyanın yerine geçtiği ifade edilmektedir (Azoulay, 2007). Bu ergenler zamanı durmuş gibi algılarlar, zamansallı̆̆a yerleşemezler çünkü zamanın aktığının farkına varamazlar. Protokollerde, az sayıda verilen hareket cevaplarına bakıldığında, hareketin dondurulmaya çalışıldığını görürüz. Örneğin, "uçmakta olan bir kuş" veya "tehlike halindeki boğalar" gibi yanıtlar hareketlerin dondurulduğunu göstermektedirler (Azoulay, 2007). Hareket açısından yoksun olan bu protokollerde duygulanımın az olması da dikkat çekmektedir. Renk yanıtları, dış dünya tarafından sunulan malzemenin içsel dünyaya alınmasını ve duyguların harekete geçirilmesini gösterirler (Azoulay, 2008). Bu tarz yanıtların olmaması veya saf renk yanıtları, uyarımların kişi tarafından kontrol edilemediğini göstermektedir. Burada dürtünü hakimiyetini sorgulamak gerekebilir (Azoulay, 2008). Söz konusu dürtüler, libidinal değil saldırgan niteliktedirler. Belki de içsel dünyanın canlılı̆̆ına ve libidinal olana saldıran bu dürtülerdir. Duygulanımın olmaması veya tasarıma bağlanamaması cansızlığa ve böylelikle ruhsal çölleşmeye sebebiyet verir (Azoulay, 2008).

Şizofreninin cansızlaştırma süreçlerine karşın, psikotik olarak nitelendirilebilecek zengin protokollerle de karşılaşılabilir. Bu protokollerin en şaşırtıcı özelliği, kişinin gerçeklik ilkesine bağlı kaldığıdır (Azoulay, 2008). Hatta dış dünya özenle zengin bir şekilde sunulmaktadır (Herrera \& Pastorini, 2017). Yanıt sayısıyla birlikte üretimin kısıtlı olmadığını görürüz (Azoulay, 2008). Herrera ve Pastorini (2017) çalışmalarında bu bireylerde dezorganizasyon ve sanrıların olmadığını vurgulamakla beraber, paranoyaya has zengin işleyişi ele almaktadırlar. Paranoya belirtileri sergileyen kişiler günlük hayatlarını sorunsuz sürdürebilirler (Herrera \& Pastorini, 2017). Ancak, yazarlara göre, paranoyanın altında kırılgan ve ciddi psikotik bir yapı bulunmaktadır. Paranoyaklar açıklarını ve bu yapıyı gizlemekte başarılıdırlar. Bu bireyler, yoğun güvensizliklerini yansıtabilecek bir diğerine, bir "günah keçisine", ihtiyaç duymaktadırlar (Herrera \& Pastorini, 2017). Dil yapsının bozulmamış olması da zengin paranoyak işleyişin özelliğidir (Azoulay, 2008). Dolayısıyla, Hermann Rorschach, Bohm, Rapoport ve Vazquez gibi araştırmacılar paranoid unsurların şizofreniye eşlik ettiklerinden bahsederler (akt., Herrera ve Pastorini, 2017). Zengin psikoz protokolleri, sınır yapıyla, hatta nevrotik yapıyla karıştırılabilir. Örnek olarak, paranoid şizofreni protokolleri ve narsisistik protokolleri karşılaştırıldı̆̆ında, benzerlikler göze çarpmaktadır. İki işleyiş de gelişmiş sözelleştirme kapasitenin yardımıyla görkemli, sembolizasyonla dolu cevaplar vermektedir. Fakat yakından bakıldığında, yoğun ve hızlanmış sözelleştirmelerin arasında dağılmış referanslar testörle olan ilişkide paranoyaya has güvensizlik, paranoid psikotik yapının göstergesidir (Azoulay, 2008). 


\section{Tartışma}

Projektif yöntemlerle birlikte psikanalitik kuram bize değerli niteliksel veriler sunmaktadırlar. Psikotik ruhsal yapılanmaların ana belirleyici özelliği 'yok olma endişesidir'. $\mathrm{Bu}$ psikotik endişenin dışında, Chabert’in değindiği gibi şizofreni protokollerinin ortak özellikleri vardır ve bu özellikler psikanalitik kuramla açıklanabilmektedir (akt., Azoulay, 2008). Ketlenmiş protokoller bize psikotik çölleşmeyle birlikte, ölüm dürtüsünü hatırlatmaktadırlar. Burada her ne kadar psikozun özelliklerine değinilip genellemeler yapıldıysa da, psikozun ve diğer ruhsal örgütlenmelerin heterojen yapılarını göz önünde bulundurmak gerekir. Insanların yekpare bir gruba indirgenmeyecekleri gibi, psikopatoloji ve kişilik değerlendirmelerinde de basite indirgeyen sinıflamalardan uzaklaşılması gerekilmektedir.

Psikoz konusuna geri dönüldüğünde, terapist olarak öncelikle kişinin ruhsal dünyasının hareketlenmesine yardımcı olmak gerekebilir. Dağılmalar, hezeyanlar ve yoğun duygular yaşanmaya başlandığında ise Federn'e göre, terapötik ortamda psikotiklerde önceki ben durumlarına geri dönüşlere izin vererek, zihinsel enerjinin korunmasına destek olmak gerekir (akt., Anzieu, 2016). Önceki ben durumları daha az zihinsel enerji yatırımı gerektirdiği için, benin sınırlarına yatırım yapılarak, bedenin ve ruhsallığın sınırları oluşacaktır. Yazara göre, "tedavi etmek [...], psikotiğin bastırmalarını kaldırmak değil, tersine bastırmalar yaratmaktır” (akt., Anzieu, 2016). 


\section{Kaynakça}

Anzieu, D. (2016). The Skin-Ego (N. Segal, Çev.) London: Karnac Books Ltd (1995).Anzieu, D., \& Chabert, C. (2011). Projektif Yöntemler (B. Kolbay, Çev.). İstanbul: Bağlam Yayıncılık (2004).

Azoulay, C. (2007). Ruhsal zamansallık, psikoz ve ergenlik: Projektif testlerin yararları (B. Alsank Sönemez, Çev.). Yansitma, 7-8, 31-51.

Azoulay, C. (2008). Rorschach ve psikoz (B. Alsancak Sönmez, Çev.). Yansıtma, 9-10, 49-56.

Emmanuelli, M. \& De Tychey, C. (2017). Manuel du test de Rorschach. Paris: De Boeck Supérieur.

Freud, S. (1953). On Dreams. In J. Strachey (Ed. and Trans.), Standard edition of the complete psychological works of Sigmund Freud (Vol. V, ss. 629-68). London, England: The Hogarth Press and the Institute of Psycho-analysis (Original work published 1901).

Freud, S. (1963). Dreams. In J. Strachey (Ed. and Trans.), Standard edition of the complete psychological works of Sigmund Freud (Vol. XV, ss. 83-242). England: The Hogarth Press and the Institute of Psycho-analysis (Original work published 1916).

Herrera, M. T., \& Pastorini, M. L. (2017). "Paranoyanın Maskesi”. Rorschach Testi'nden elde edilen Sonuçlar (H. Beşikçi, Çev.). Yansıtma, 27, 109-123.

İkiz, T. (2016). Rorschach Test Eğitimi: Psikoz ve psikotik protokoller, 9. oturum [Basılı metin]. Rorschach ve Projektif Testler Derneği, Beşiktaş, İstanbul.

İkiz, T. (2017). Rorschach Testi psikanalitik yorum kodlama ve uygulamalar. İstanbul: Bağlam Yayıncilik.

Lerner, H. D., \& Lerner, P. M. (1982). A comparative study of defensive structure in neurotic, borderline, and schizophrenic patients, Psychoanalysis and Contemporary Thought, 5, 77-115.

Lerner, P. M. (2007). On preserving a legacy: Psychoanalysis and psychological testing Psychoanalytic Psychology, 24, 208-230.

Mijolla, A. D. (2005). International dictionary of psychoanalysis. Detroit: Thomson Gale. Morris, C. G. \& Maisto, A. A. (2007). Understanding Psychology. United States: Prentice Hall.

Pomerantz, A. M. (2013). Clinical Psychology. United States: SAGE Publications. Société du Rorschach et des Méthodes Projectives de Langue Française (t.y.). Retour sur l'histoire de la société du Rorschach. Erişim: https://www.societerorschach.org/historique/

Sugarman, A., \& Kanner, K. (2000). The contribution of psychoanalytic theory to psychological testing, Psychoanalytic Psychology, 17, 3-23.

Tuber, S. (2012). Understanding personality through projective testing. Lanham, MD: Jason Aronson. 


\section{An Elaboration of Psychosis with the Rorschach Test as a Projective Approach}

\section{Summary}

\section{Introduction}

As a projective method of personality investigation, an introduction to the Rorschach Test and its findings related to psychosis has been provided. The Rorschach Test was integrated into the psychoanalytic theory by many important French researchers using Rapaport and Schafer's preliminary publications as base. Along with the Thematic Apperception Test (TAT), it contains elements triggering perceptive and cognitive processes. The 10 cards created by $\mathrm{H}$. Rorschach varies in shape, color and coherence. During test administration, based on Freud's free association method, the responses are directed in a limited way and every detail is noted. Afterwards, every response is scored according to the certain categories in order to compare the results with the statistical data. Besides the structural statistical analysis, content analysis is carried out in parallel with the psychoanalytic literature. While administering projective tests, the main aim is to understand how the real and phantasy, internal and external, perception and cognition of a person are organized. Beyond pathological personality structures, statistical and content analyses provide us rich information related to the individual's internal life and dealing with reality. Compared to the neurotic and borderline personality structures, the protocol of a psychotic has different attributes. One of the core aspects of psychosis, according to the psychoanalytic literature, is the 'annihilation anxiety' which can be also found among the Rorschach responses. This psychotic anxiety confronts the psychotic individual with an immense fear of fragmentation and disintegration. Besides this 'annihilation anxiety', five common psychotic features explained by psychoanalytic theory are illustrated in the application area of the Rorschach Test. At the center of these five common features, Palem's studies on schizophrenia and Chabert's reclassification of his findings take place. Schizophrenia can be characterized by impairment in reality testing, cognitive processes, identity and body image, and an inadequacy in protective shield against stimulation. According to Anzieu and many other psychoanalytic thinkers, this personality organization rests upon pregenital traumas and incompetence of the maternal figure. The incompetent maternal representation is clearly projected onto the Rorschach Test. Paranoid schizophrenia, compared with schizophrenia, is generally more stable personality structure scoring high on reality testing, cognitive processes and the other aspects. However, the fragile psychotic bases are unveiled from time to time under the influence of hallucinations. When paranoid characters accompany schizophrenia, distrust, persecution 
and conspiracy phantasies might occur. Although paranoid schizophrenic structures are more adaptable to reality, one should not forget the fact that a manifold of personality structures exist. Projective tests might be useful for categorizing personalities, but understanding the dynamic internal processes and determining the seriousness of the pathology to help the individual adapt to the reality should be more important for clinicians. Protocols characterized by inhibition and psychic drought carry the danger of the death drive. These should be used in order to intervene and revive the person during the therapeutic process. All in all, the Rorschach Test offers a detailed analysis of the underlying factors of a specific symptom or personality organization which can be used at the beginning of the therapeutic process to adopt a certain approach. 